\title{
A Safety Monitoring System for Power Tower Structure
}

\author{
Xin Zheng \\ Electric power research institute of Yunnan power grid \\ Corporation \\ Kunming, China \\ e-mail: 283925003@qq.com \\ Zhixiong Liu \\ School of Electrical Engineering, Wuhan University \\ Wuhan, China \\ e-mail: zxliu@whu.edu.cn
}

\author{
Zhangqin $\mathrm{Wu}$ \\ Electric power research institute of Yunnan power grid \\ Corporation \\ Kunming, China \\ e-mail: zsswzq@163.com \\ Jin Wang \\ Electric power research institute of Yunnan power grid \\ Corporation \\ Kunming, China \\ e-mail: lauerth@126.com
}

\begin{abstract}
This paper studies the on-line monitoring safety system of the power tower structure. Firstly, it introduces the necessary of this system, then introduces the principle of stress measurement and the monitoring system structure. Secondly, it gives the method to calculate the safety index of tower structure. Finally, it describes the implementation and steps of the proposed method, and gives experimental results based on a series of measurement data samples from sensors.
\end{abstract}

Keywords-power tower structure; sensors;monitoring; stress;reliablity

\section{INTRODUCTION}

How to prevent the occurrence of such incidents has been the focus of the research on transmission lines safety in these years [1-3].The steel structures of power tower will have a certain degree of deformation when there is an external force applied on them. Generally, this deformation is so small that it is difficult to observe it directly, but it can be measured by stress sensors.

In the transmission tower-line system, towers should bear itself weight and the weight of the lines, produce a certain tension load to hang the lines, consequently, the stress distribution in transmission towers reflects not only the mechanical load of the transmission, but also the condition of resistance tension in lead wires and ground wires. Therefore, the reliability assessment of the power tower structure considering various conditions has important theoretical and actual significances [4-8], so, online monitoring of stress of transmission tower is necessary, it can provide on-line monitoring of stress at critical position on transmission tower and the on-line safety assessment. In this paper, a on-line safety monitoring system for power tower is designed.

\section{PRINCIPLE OF STRESS MEASUREMENT}

Stress measurement in this paper means the static stress measurement. Stress related effect can be obtained by resistance strain sheet, photoelastic sheet, string wire vibration, mechanical transmission and hydraulic transmission therefore stress value can be worked out. For tower's stress measurement, resistance strain stress sensor is used. Differential half-bridge is introduced in this chapter and the stress measurement principle is described as follow.

Four resistance strain gauges are mounted as shown in Fig .1 (a) and formed a bridge as shown in Fig .1(b).It can be introduced from the basic physical concept of resistance and the position of strain gauges in Fig .1(a) that:

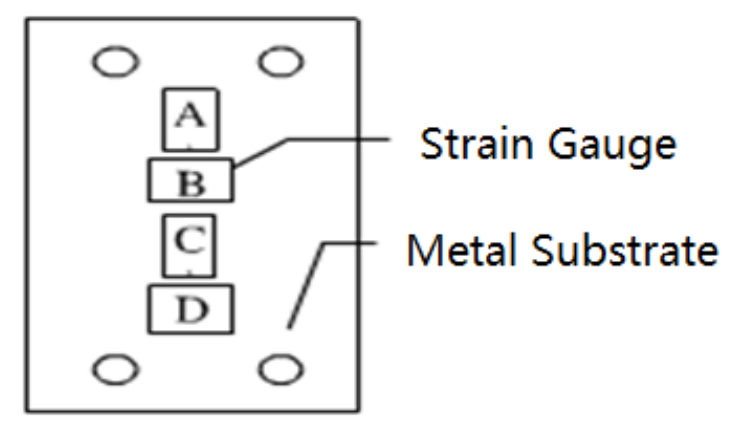

(a)

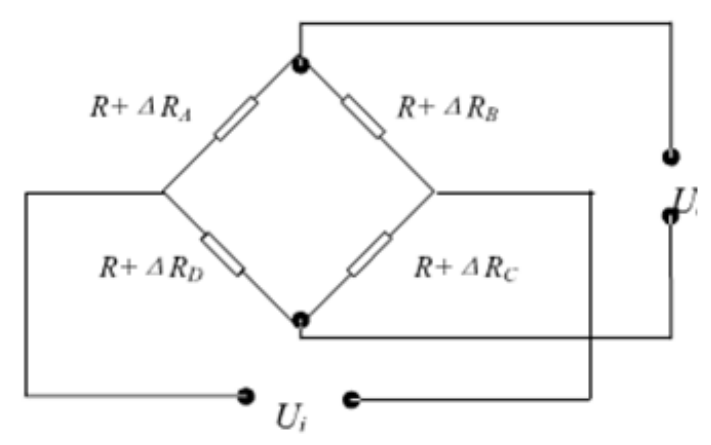

(b)

Figure 1. Principle of stress measurement 


$$
\begin{gathered}
\frac{\Delta R_{A}}{R}=\frac{\Delta R_{C}}{R}=k \varepsilon \\
\frac{\Delta R_{B}}{R}=\frac{\Delta R_{D}}{R}=-\mu k \varepsilon \\
\frac{U_{0}}{U_{i}}=\frac{(1+u) k \varepsilon}{2+(1-u) k \varepsilon} \\
\varepsilon=\frac{2}{k\left[(1+u) \frac{U_{i}}{U_{0}}-(1-u)\right]}
\end{gathered}
$$

where $U_{i}$ is the real-time measured voltage value, and other parameters are known, therefore the corresponding stress can be obtained from $U_{i}$. The sensitivity coefficient $k$ can be further verified in practice. $\varepsilon$ is the strain to be measured and $\mu$ is Poisson's ratio of the material.

Stress $\sigma$ can be obtained from knowledge relating to metal material science:

$$
\sigma=\varepsilon E
$$

where $\mathrm{E}$ is the fixed parameter of metal material, and then stress can be worked out:

$$
\sigma=\frac{2 E}{k\left[u-1+(1+u) \frac{U_{i}}{U_{0}}\right]}
$$

\section{THE SYSTEM STRUCTURE}

The monitoring system is composed of stress sensors, front-end acquisition processors and backend server. Front-end acquisition processor is responsible for acquiring and processing data from stress sensors, correcting the data based on temperature, coding them after stress calculation and finally sending to backend server. In this system, these front-end acquisition processors are designed with DSP architecture, they communicate with the backend sever through GPRS/CDMA data network. The system architecture is showed in Fig .2.

Power tower has a complex towering structure, so its safety (reliability) is greatly influenced by many factors, such as wind load and ice load. Meanwhile, it consists of a large number of main bars, helical rods, diagonal braces and other components; therefore, it is very difficult to solve its whole structural reliability directly. Considering main bars account for a large proportion of the weight of the tower in the structural design, they are the main loadbearing structures of the tower. Therefore, for the sake of simplicity, tower structure can be considered damaged when one of the main bar yielding occurred. We used the safety index of main bars instead of the safety index of whole power tower in engineering, moreover, the safety of power tower structural system is determined by its weakest mode.

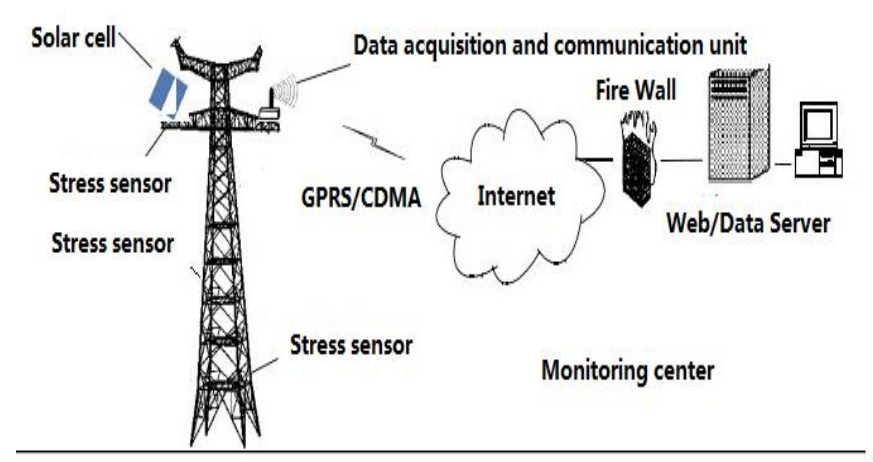

Figure 2. The system structure

In the on-line monitoring system, the layout of stress sensors needs to be primarily addressed since different towers would show different stress condition under different working condition. A method to design the layout of stress sensors in the tower using finite element analysis is presented in our another paper[1]. By calculating the stress distribution of different components of the tower under typical working condition, it can obtain the positions with relatively higher failure probability, then stress sensors will be installed in these points to monitor the power tower. For a $500 \mathrm{kV}$ oxytropis tower, the layout of stress sensors can be obtained used methods described in [1]. By relying on drawing and construction data, analysis modeling is performed by using finite element method for towers to be monitored. The model consists of 513 nodes and 1298 beam elements. The tower is securely fixed to the foundation and it is assumed that the materials are under the stage of flexible working [1], shown as following:

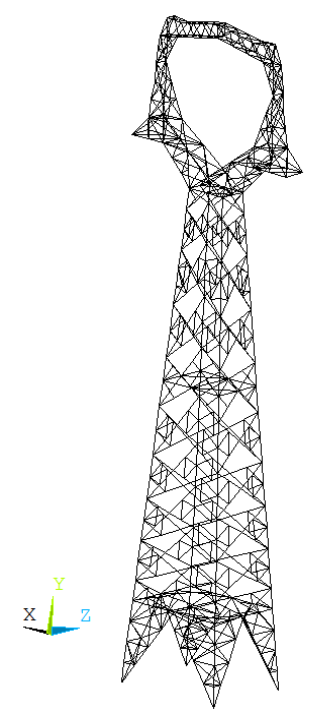

Figure 3. Finite element model of the structure of transmission tower 
By the calculating results according to [1], in our designed monitoring system, 12 stress sensors are installed symmetrically on the main bars, as shown in Fig .4

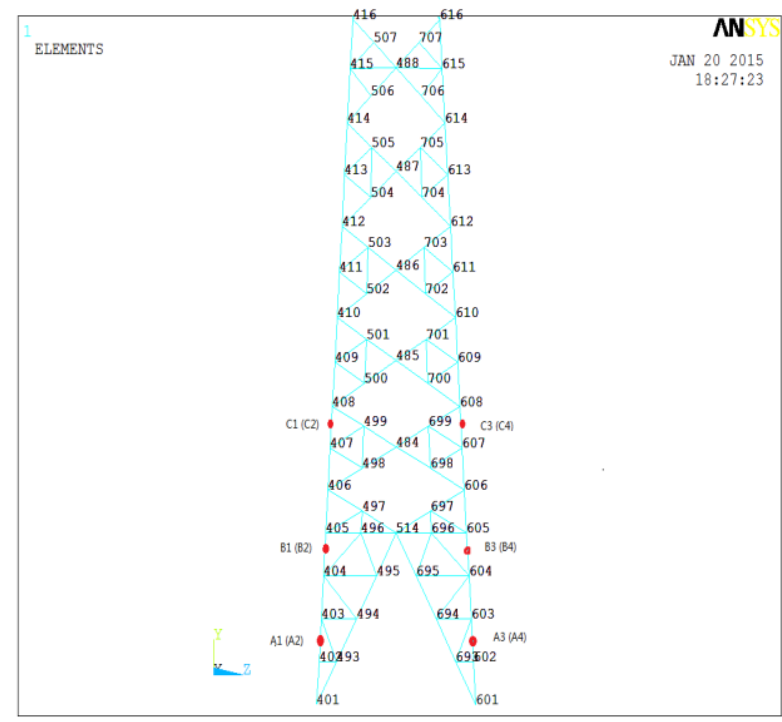

Figure 4. Positions of stress sensors

\section{SAFETY EVALUATION OF TOWER MAIN BARS}

In the reliable condition assessment on the power tower, the main task is to judge its structures reliability. Structural reliability is decided by some random factors, such as load types, material strength, geometry of the components. Usually, these random factors are called basic variables, expressed by $x_{i}(i=1,2, \ldots, \mathrm{n})$. The limit state equation of structure is[4-6]

$$
Z=g\left(x_{1}, x_{2}, \ldots, x_{n}\right)=0
$$

The structure system's function of transmission tower can be expressed as follows:

$$
Z=g(S, R)=R-S
$$

where $\boldsymbol{R}$ is the strength of the structure, $\boldsymbol{S}$ is the stress applied on the structure, and the status of structure is decided by the value of $\boldsymbol{Z}$, which can be showed as follow :

$$
\left\{\begin{array}{lr}
Z>0 & \text { Safe status } \\
Z=0 & \text { Extern status } \\
Z<0 & \text { Failed status }
\end{array}\right.
$$

So, the structure system's function of main bars of tower structure can be expressed as follows:

$$
Z=g(S, R)=R-k * S
$$

where $k$ is safety coefficient[4,5], $\boldsymbol{R}$ is the strength of the steel structure, $\boldsymbol{S}$ is the stress applied on the structure.Assuming $\boldsymbol{R}$ and $\boldsymbol{S}$ are continuous random variables, which are independent each other and fitting normal distribution, then $\boldsymbol{Z}$ is also fitting normal distribution, its mean and standard deviation are:

$$
\begin{gathered}
u_{Z}=u_{R}-k * u_{S} \\
\sigma_{Z}=\sqrt{\sigma_{R}^{2}+k^{2} * \sigma_{S}^{2}}
\end{gathered}
$$

So, the failure probability of the structure is

$$
P_{f}=P\{z<0\}=F_{Z}(0)=\Phi\left[\frac{Z-u_{Z}}{\sigma_{Z}}\right]
$$

The reliability of the structure can be given by

and

$$
\beta=\frac{u_{Z}}{\sigma_{Z}}=\frac{u_{R}-k * u_{S}}{\sqrt{\sigma_{R}^{2}+k^{2} * \sigma_{S}^{2}}}
$$

$$
P_{f}=\Phi[-\beta]
$$

or

$$
\beta=\Phi^{-1}\left(1-P_{f}\right)
$$

\section{EXPERIMENT AND RESULT}

For example, a $500 \mathrm{kV}$ oxytropis power tower is designed to be installed 12 stress sensors as Fig .3 in the on-line monitoring system. The safety index of power tower structure at time $t$ can be obtained as follows:

1) If 12 data sets have arrived at the sever from sensors at the time $t$, the mean and variance can be calculated for each dataset, i.e. $\left(\mathrm{u}_{1}, \sigma_{1}\right),\left(\mathrm{u}_{2}, \sigma_{2}\right), \cdots,\left(\mathrm{u}_{12}, \sigma_{12}\right)$. Because only yield stresses are considered, and these seniors are installed symmetrically in the tower, so only 6 data sets of compressive stress used here for calculating the safety of power tower .

2) For the main bar of oxytropis tower, the Q345 steel is used. The yield strength of main bar is assumed to be log-normal distributed [9][10], which can be transformed to be a nomal variable. After transformed, the prams in eqn.(13): $\mathrm{u}_{R}=380.21 \mathrm{MPa}, \sigma_{R}=54.75$ MPa. So, it can be obtained from eqn.(13):

$$
\beta_{i}=\frac{u_{R}-k * u_{S}}{\sqrt{\sigma_{R}^{2}+k^{2} * \sigma_{S}^{2}}}=\frac{380.21-1.5 * u_{S}}{\sqrt{54.75^{2}+1.5^{2} * \sigma_{S}^{2}}}(16)
$$

3) There are six compress stress samples (which value are negative) in the Table. 1 in time $t$. So, the safety index of each bar installed with sensors can be calculated according to eqn.(16). The result is shown in Table.1. We can see that the min value of safety index of the main bars 
is 3.09. As mentioned before, the safety index of tower structural system is determined by its weakest main bar, so, we can obtain that the safety index of tower structure is 3.09 at time $t$.

TABLE I. COMPRESSIVE STRESS SIMPLES AND RELIABILITY

\begin{tabular}{|c|c|c|}
\hline $\begin{array}{c}\text { Mean value } \\
(\mathbf{M P a})\end{array}$ & Variance(MPa) & Safety index \\
\hline-96.04 & 12.35 & 4.08 \\
\hline-130.10 & 15.35 & 3.12 \\
\hline-121.55 & 14.28 & 3.37 \\
\hline-107.76 & 12.93 & 3.76 \\
\hline-124.92 & 13.51 & 3.30 \\
\hline-128.73 & 17.12 & 3.09 \\
\hline
\end{tabular}

\section{CONCLUSION}

This study proposed a on-line safety monitoring system for transmission tower structure. It introduced the principles of this system, described how to evaluate the safety index of tower structure system based on measurement stress samples. The designed on-line assessment system will be installed later in Yunnan Province, China. Some problems would be encountered and we would continue to improve and optimize this system in practice.

\section{REFERENCES}

[1] J Wang, Z.X Liu, Z.Q Wu, et al." Research on on-line monitoring of transmission tower stress," Applied Mechanics and Materials. vol.668-669, pp 948-952, 1999.

[2] Antanas Kudzys. "Safety of power transmission line structures under wind and ice storms," Engineering Structure .vol. 28, pp 682-689,2006

[3] M.H Li, Z.L Li, D.K Yu. "The system reliability analysis of $1000 \mathrm{kV}$ UHV transmission tower based on moment method," Energy Procedia .vol. 16, pp 166-171, 2012.

[4] Ricardo O. Foschi. "Reliability theory and applications to risk analysis of power components and systems," Electrical Power and Energy Systems. vol.26,pp. 249-256..2004

[5] Mehdi Modares, Shyamala Venkitaraman. "Reliability analysis of a microwave tower for fluctuating mean wind," Reliability Engineering and System Safety vol.;67.pp.257-267.2000

[6] J Li, J.B Chen and W.L Fan. The equivalent extreme-value event and evaluation of the structural system reliability. Structural Safety, vol.29, pp.112-131.2007

[7] Mehdi Modares, Shyamala Venkitaraman."Reliable condition assessment of structures using hybrid structural measurements and structural uncertainty analyses," Structural Safety,vol52, pp.202 208.2015

[8] B Sudret, G Defaux, M Pendola."Time-variant finite element reliability analysis - application to the durability of cooling towers," Structural Safety ,vol.27,pp.93-112.2005

[9] DL/T 5154-2002,Techinical regulation of design for tower and pole structures of overhead transmission line. Beijing: Chinese electric power publishing house;2002( In Chinese)

[10] GB 50009-2001, Load code for the design of building structures. Beijing: Chinese construction and industry publishing house;2002. (In Chinese). 